DOI: $10.5902 / 198468628535$

\title{
A dimensão da beleza física na concepção de pessoas com cegueira congênita
}

The uniqueness of congenital blindness the body perception

A dimensão da beleza física na concepção de pessoas com cegueira congênita

\section{* Everton Luiz de Oliveira}

Professor doutor do Centro Universitário UNIFAFIBE, Bebedouro, São Paulo, Brasil.

Oliverira-everton@hotmail.com

\section{** Fátima Elisabeth Denari}

Professora doutora da Universidade Federal de São Carlos (UFSCar), São Carlos, São Paulo, Brasil. fadenari@terra.com.br

Recebido: 09 de agosto de 2017

Aprovado: 02 de outubro de 2018

\section{RESUMO}

Ao observar que as pessoas com cegueira congênita apresentam processos de aprendizagem e de simbolização singulares, despertou-se para a inquietação de que, em um mundo regido por formas visuais/imagéticas, estas poderiam ou não apresentar conceitos sobre beleza. Desta forma, este estudo, de caráter qualitativo e de cunho descritivo, destinou-se a investigar e compreender as representações sociais de corpo a partir da concepção de pessoas com cegueira congênita. Para obtenção dos dados optouse por entrevista semiestruturada, permitindo que todo o conteúdo fosse analisado por meio da análise de conteúdo. Os resultados apontam para a maneira generalizante com que a beleza corporal é apreendida nas práticas cotidianas pelas pessoas com cegueira. Por fim, o tato, a linguagem e a audição se mostraram mecanismos importantes para 0 desenvolvimento das representações sociais de corpo e para o estreitamento com o mundo sensível sobre o qual se apresenta a beleza nas práticas e objetivações sociais de pessoas com cegueira.

Palavras-chave: Corpo; Cegueira Congênita; Beleza.

\section{ABSTRACT}

Noting that congenitally blind people have unique processes of learning and symbolizations, it leads to a concern that they might or might not present concepts of beauty in a world ruled by visual/imagery forms. Thus, this qualitative and descriptive study intended to investigate and understand body social representations from conceptions of people with congenital blindness. For data acquisition we chose a semi-structured interview, allowing the entire content to be analyzed by content analysis. The results indicated the generalizing way that 


\section{DOI: $10.5902 / 198468628535$}

the physical beauty is captured by blind people on daily practices. Finally, touch, language and hearing proved to be important mechanisms for development of both body social representations and the approach to the sensible world which presents beauty on practices and social objectifications of people with blindness.

Keywords: Body; Congenital blindness; Beauty.

\section{RESUMEN}

Al observar que las personas con ceguera congénita presentan procesos de aprendizaje y de simbolización singulares, se despertó para la inquietud de que, en un mundo regido por formas visuales / imagéticas, éstas podrían o no presentar conceptos sobre belleza. De esta forma, este estudio, de carácter cualitativo y de cuño descriptivo, se destinó a investigar y comprender las representaciones sociales de cuerpo a partir de la concepción de personas con ceguera congénita. Para obtener los datos se optó por entrevista semiestructurada, permitiendo que todo el contenido fuera analizado por medio del análisis de contenido. Los resultados apuntan a la manera generalizante con que la belleza corporal es aprehendida en las prácticas cotidianas por las personas con ceguera. Por último, el tacto, el lenguaje y la audición se mostraron mecanismos importantes para el desarrollo de las representaciones sociales de cuerpo y para el estrechamiento con el mundo sensible sobre el que se presenta la belleza en las prácticas y objetivaciones sociales de personas con ceguera.

Palabras clave: El cuerpo; Ceguera Congénita; Belleza.

\section{Introdução}

$\mathrm{Na}$ contemporaneidade ter um corpo belo mais do que adjetivo, qualidade ou atributo passou a ser uma necessidade, uma cobrança, anulando os sujeitos sociais e históricos pelo reconhecimento e contemplação de um sujeito que agora passa a ser um corpo, 0 corpo que chega e se faz presente, corpo que deve ser belo para ser social e humano.

Numa sociedade regida pelo consumo o desejo por um corpo belo/ideal encontrou coro, este se tornou produto nas prateleiras do mercado do corpo e do fitness, forjado à custa de sacrifícios físicos e financeiros, marcando uma nítida (mas não declarada) distinção social, beleza projetada no e pelo consumo de bens e produtos, é privilégio, tem dono e se reflete no e pelo corpo.

Brasílio (2007, p.40) identificou em seu estudo que para 93\% dos jovens entrevistados, a exposição constante de modelos corporais pelas revistas, televisão e cinema contribuiu para a divulgação de um modelo ou padrão corporal hegemônico. Ainda, para este referido autor, o padrão de beleza - magro, jovem e branco - atinge as diversas classes sociais, ao passo que neste processo os corpos são educados para coadunar com práticas e rotinas que vislumbrem a obtenção de corpos socialmente desejados (BRASILIO, 
DOI: $10.5902 / 198468628535$

2007). Em tal interregno histórico, a beleza estaria associada a inúmeras formas de sociabilidade (Novaes; Vilhena (2003).

Novaes (2008) destaca, ainda, que possuir o modelo de corpo idealizado, aceito e valorizado socialmente, representaria a conquista de um corpo "em forma", em que não se alojassem gorduras, desvios ou excesso de peso. Nessa medida, figurando entre os piores tipos de desleixo com o corpo tem-se o acúmulo de gordura corporal, traduzindo um relacionamento inadequado com o corpo e relegando à pessoa obesa o espaço da feiura. Uma época em que é declarada "tolerância zero" com a gordura.

Desta forma, entende-se que a beleza pronunciada pelo corpo seria, possivelmente, decisiva na construção das relações interpessoais e dos vínculos afetivos estabelecidos pelos sujeitos nos mais variados espaços sociais e momentos da sua vida, tais como escolas, trabalho, clubes, academias de ginástica, festas, viagens, passeios entre outros(as).

O corpo representa uma multiplicidade de formas e sentidos que o configuram como uma linguagem, comunicando e expressando valores de uma dada cultura e sociedade. $O$ homem, antes mesmo das palavras, já se comunicava por meio do corpo e, na contemporaneidade, cada vez mais se tem provas de que o corpo "fala" (MATTHIESEN et al., 2008).

Para Berger (2006) e Vigarello (2006) as buscas desmedidas para alcançar um modelo de corpo idealizado e reificado, a cobrança por um padrão de beleza hegemônico, a construção de arquétipos do tipo musculoso e atlético (para o homem) ou magro e sarado (para as mulheres), o anúncio e naturalização de um padrão de beleza que vilipendiaria todas as outras constituições corporais e estéticas, corroboraram para a construção de um fenômeno chamado de "culto ao corpo", tendo surgido no final do século XX.

Isto posto, denota-se a importância das imagens e do mundo visual para a disseminação dos modelos ou padrões de beleza historicamente aceitos e validados, compreendendo que ao mesmo tempo em que essa beleza desfila sobre o olhar atendo da contemporaneidade, fixam-se as representações sociais do belo que exercem poder e influencia nas práticas, atitudes e convívios sociais.

Ao observar-se que as pessoas com cegueira congênita apresentam processos de aprendizagem e de simbolização diferentes daqueles empreendidos por pessoas que gozam da sensação visual e, ainda, como aponta Batista (2005) por não aprendem nem mais e nem menos, apenas diferentemente; despertou-se para a inquietação de que num 


\section{DOI: $10.5902 / 198468628535$}

mundo regido essencialmente pelas formas visuais e imagéticas, os cegos poderiam apresentar singularidades nas representações ou conceitos de beleza e de corpo.

Laplane e Batista (2003) advertem que alguns conceitos e conhecimentos não são possíveis de ser aprendidos, descobertos ou ensinados pelo tato por configurarem situação em que o toque seria proibido ou pouco convencional, como é o caso do corpo ou de algumas partes dele, isto pensado na relação com o corpo do outro, aquele que é diferente e deveria ser entendido.

Para tanto, Lebedeff (1994) enuncia algumas dificuldades encontradas pelo cego para representar o corpo do outro e identifica como é nebuloso e instigante o campo das representações sociais de beleza no universo da pessoa com cegueira, "[...] e a anatomia do sexo oposto? Como o ocorre o conhecimento do corpo do outro, se o toque é proibido na nossa cultura? Será que a sexualidade do cego é uma sexualidade sem estética, sem altos nem baixos, gordos ou magros, não importa a cor dos olhos? (LEBEDEFF, 1994, p.31).

$\mathrm{Na}$ busca por um referencial teórico que pudesse consubstanciar incursões investigativas e conhecimentos no campo resignado por fenômenos em torno do corpo e do universo da cegueira e, ainda, a sua importância nos processos sociais, afetivos e de desenvolvimento psicossocial, cognitivo e comportamental destas pessoas, recorreu-se a teoria das Representações Sociais.

As representações sociais tratam dos conceitos, significados e interpretações formados pelo senso comum sobre determinados objetos, coisas ou fenômenos em um espaço/tempo definidos no interior de um grupo social específico, agindo diretamente nas práticas cotidianas dos sujeitos (MOSCOVICI, 2004).

Tratar-se-á, especificamente, das representações sociais da beleza a partir da realidade e objetivações de adolescentes com cegueira congênita, utilizando a literatura para explicar quais as implicações destas representações no convívio e entendimento do outro e do mundo no qual habita.

Por meio das representações sociais o sujeito reinterpreta tudo aquilo que é recebido do exterior, quando se relaciona com o meio por interações sociais. Assim é possível ressignificar aquilo que é recebido do exterior, no contexto de valores, códigos e condutas sociais presentes no grupo social de que faz parte, desta forma a Representação Social se torna decisiva na elaboração e escolha dos comportamentos sociais. 
A partir deste constructo teórico e analítico, destaca-se que o objetivo do presente estudo foi apreender as significações e representações que as pessoas com cegueira apresentam acerca do corpo e da beleza.

\section{Método}

Este estudo é de caráter qualitativo e cunho descritivo destinou-se ao conhecimento dos entendimentos sobre a representação social do corpo (fenômeno) para jovens com deficiência visual (população). Segundo Vilelas (2009, p.121)

(...) a preocupação primordial dos estudos descritivos radica em descobrir algumas características fundamentais de conjuntos homogêneos de fenómenos. [...] descreve uma realidade. O investigador acerca-se da realidade, procurando descrever e documentar os fenômenos que nela acontecem.

Complementarmente, os autores Sampieri, Collado e Lucio (2006, p.7) apontam que nas pesquisas qualitativas "em vez de clareza sobre as questões e hipóteses preceder à coleta e análise dos dados (como na maioria dos estudos quantitativos, pelo menos em intenção), os estudos qualitativos podem desenvolver questões e hipóteses antes, durante ou depois da coleta e da análise".

A pesquisa foi aprovada junto ao Comitê de Ética em Pesquisa em Seres Humanos da Universidade Federal de São Carlos sob o CAAE: 0195.0.135.135-10.

\section{Participantes}

Com o propósito de selecionar os participantes para a efetivação deste estudo, realizou-se um mapeamento junto a duas Diretorias Regionais de Ensino da região central do Estado de São Paulo, visando o levantamento e identificação de todos os alunos com cegueira congênita matriculados no ensino médio e que tivessem disponibilidade e interesse em colaborar e/ou participar do estudo, formalizando-o por meio da assinatura dos alunos e dos pais/responsáveis de um Termo de Consentimento Livre Esclarecido (TCLE). Com isso, obtive-se uma amostra composta por três alunos, ambos do sexo masculino, enquadrados em uma faixa etária compreendida entre 18 e 19 anos.

\section{Coleta de dados}

As entrevistas foram realizadas em três escolas estaduais diferentes, estando ambas em municípios diferentes da região central do estado de São Paulo. Essas escolas foram selecionadas por serem as únicas com matriculas de alunos com cegueira congênita no ensino médio. A opção por utilizar as escolas como espaços 


\section{DOI: $10.5902 / 198468628535$}

para a coleta de dados deu-se pelo fato destas serem espaços/ambientes familiares aos alunos com cegueira congênita participantes do estudo e de fácil acesso aos mesmos. Além disso, inicialmente tinha-se a convicção de que a escola facilitaria também o contato direto com os pais e com os alunos, passando para ambos, segurança e credibilidade quanto ao estudo a ser realizado.

Inicialmente, no encontro com os pais e alunos, explicou-se detalhadamente 0 estudo e as dúvidas que surgiram naquele momento. Mediante concordância com procedimentos e demais disposições apresentadas sobre o estudo, os pais e/ou responsáveis assinaram um Termo de Consentimento Livre e Esclarecido ${ }^{1}$ autorizando e formalizando a participação dos respectivos alunos.

\section{Análise dos dados}

As entrevistas foram todas transcritas na íntegra, inclusive os erros gramaticais, linguísticos e as gírias e vícios de linguagem, dando desta forma maior credibilidade e importância às falas dos entrevistados, reconhecendo a validade de todo o material produzido a partir destas entrevistas. Após a transcrição o conteúdo das entrevistas foi analisado por dois juízes independentes (alunos do Programa de Pós-Graduação em Educação Especial) para assegurar a confiabilidade dos dados.

Para analisar os dados utilizou-se a análise de conteúdo proposta por Bardin (1977), especificamente, a análise de conteúdo categorial. Essa técnica consiste em uma sequência de operações pelas quais certas unidades são identificadas e classificadas de modo a permitir a descrição sistemática do conjunto ou produção, essas unidades podem ser divididas em unidades de registro ou de conteúdo (BARDIN, 1977).

Desta feita, foram elaboradas duas categorias, dentro das quais foram inseridas as questões utilizadas no roteiro (subcategorias) e, ainda, tendo suas respectivas respostas organizadas nesse espaço. A organização das questões dentro de cada uma destas categorias deu-se a partir de proximidades temáticas.

\footnotetext{
${ }^{1}$ A solicitação da assinatura do TCLE por parte dos país/responsáveis mesmo os participantes sendo maiores de idade deve-se à necessidade de atender ao pedido do Comitê de Ética em Pesquisa em Seres Humanos da UFSCar, não cabendo ao pesquisador imprimir qualquer tipo de análise ou questionamento quanto ao cumprimento desta solicitação.
} 
Resultados

A seguir serão apresentados os resultados das entrevistas, de maneira que para cada categoria colocada no topo, seguem-se as questões (subcategorias) a estas relacionadas, bem como as respostas mantidas nas formas como foram declaradas pelos participantes, os quais receberam nomes fictícios para preservar identidades e manter o requerido rigor ético-acadêmico.

\section{Representação social do corpo}

Q1 - Como é para você um corpo ideal/perfeito?

$A i$, ah... não muito gordo. Pessoa assim, nem muito gorda, nem muito magra, mais ou menos. (Paulo)

Então, fica meio difícil, porque eu sou assim... eu, não importa se a pessoa é baixinha, se é meio gordinha, se é cheinha, se é gordinha, se é magra, se é alta (...) Particularmente, eu prefiro mais a cheinha viu. (Mauro)

Bom, corpo ideal seria que nem uma pessoa né, magra, mas não magra magra, mas um corpo médio, magra, tem que ser alta né, sarada, tem que ser uma pessoa musculosa, aqueles músculos assim sabe de atleta, assim nesse estilo, porque ai sim é que eles vão falar, que eles vão reparar né, eles vão olhar a sua aparência e vão perceber né a pessoa bonita, bonita tal, ela se cuida pra se tornar uma pessoa muito bonita né, e, um corpo muito bonito. (José)

Q2 - A televisão ajuda a construir esse padrão ou modelo de beleza? De que forma?

É porque é assim, não é todo mundo que é igual. Uns gostam, porque uns gostam do corpo de um jeito e outros gostam de outro. Tem até aquele famosos que fazem plásticas para mudar não sei o que, tudo o corpo, pra ficar mais bonito (...) Ah, mostrando a cirurgia que as pessoas fazem para mudar. (Paulo)

Olha, eu vou te falar uma verdade pra você, essa mulherada ae eu acho que, sei lá cara, qualquer coisa que vê na tevê quer fazer. Acho que não é por ae (cara de desaprovação), tem que ser o que é. Não, tem que se maquiar? Tem, fica chique. Tem que colocar brinco? Tem, fica chique. Mas agora fazer plástica, colocar silicone, pra que isso? (...) Eu acho que não tem que colocar silicone, não tem que colocar, tem que ser o que é. (...) É, vê uma atriz lá com biquininho meio né ... ae quer comprar igual. (Mauro)

Sim, influência muito. Inflência, a televisão sim. Em novelas, por exemplo, mostra muito né a pessoa se exibindo né, tal, mostra as loiras, as morenas, as brancas, as pretas e a televisão mostra, mas eu acho assim, que a mídia força um pouco, a televisão eu acho que ela força também, vamos fazer a pessoa ficar bem bonita pra ela arrasar naquele lugar, pra se mostrar, pra todo mundo olhar. (José)

Q3 - Existem diferenças entre os corpos masculinos e femininos com relação aos seus padrões ou tipos de beleza? Se sim, quais?

A mulher é mais vaidosa e o homem é mais sossegadão. (Paulo) (Mauro)

Só pela humildade, pela simpatia, vixe (com relação ao homem).

Corpo da mulher? Ah, o rosto por exemplo. (Mauro) 
DOI: $10.5902 / 198468628535$

Olha, uma mulher assim, as mulheres que tem uma sobrancelha bonita, olhos verdes ou castanhos ou azuis (risos) é assim, tem mulher que usa óculos porque não enxerga de perto, mas assim, tem que ser uma mulher é né assim, uma mulher bonita, unhas feitas ou não, ou deixar a unha de qualquer jeito, cabelo comprido ou preso, é cheirosa claro, a pessoa tem que tá perfumada. Uma mulher assim, musculosa, tem mulher que faz academia né? Faz muita academia, faz esteira, abdominal...(José)

Ele tem que ter um pouco mais cuidado pra ele né. (...) o corpo bonito né, alguns homens são saradões, eles não são, é, tem homens que se depilam, que não são tão peludos, porque querem, querem se depilar pra ele se sentir mais a vontade. Tem homens que não deixam a barba crescer muito, vê que já tá crescendo, não, que eu vou depilar, eu vou corta aqui. E ele tem que ter dentes muito bem escovados (risos). Você entendeu? E, é assim, o que eu acho do homem e da mulher é dessa forma que eu falei pra você agora. (José)

\section{$O$ toque e a linguagem na representação do corpo}

Q4 - Dá para saber como é o corpo de uma pessoa que você acabou de conhecer?

Eu gosto muito das mãos (...) acho que apertando as mãos delas, sentindo as mãos delas. Ajuda é, acho que a gente fica imaginando como ela é. (Paulo)

Um exemplo, assim quando eu acabo de conhecer eu não pergunto, dá vergonha e é meio chato, ae eu pergunto para alguém que tá comigo como essa pessoa é. (Mauro)

Acho sim, claro que tem. Mesmo que eu não toque na pessoa, mas dá pra imaginar como que ela é né, ela é bonita mesmo eu não tocando, mas dá pra, vem assim uma imaginação. Eu imagino nessa forma. (José)

Q5 - Você costuma perguntar para outras pessoas sobre como elas são fisicamente?

Eu tenho vergonha, pergunto não. (Paulo)

É. Ai depois de algum tempo, que eu tava assim, com bastante amizade, ai eu pergunto para aquela pessoa mesmo como ela é. Pra mim ver se é o mesmo que o outro falou. (Mauro)

Isso, eu pergunto como ela é, é... se ela é magra ou se ela é gorda, é baixa, é alta, ela tem cabelo, se ela é loira ou morena, cabelo comprido ou curto e ... porque assim a gente consegue definir, é, a imagem assim de cada uma, de cada pessoa que passa a gente consegue saber, é, definir a pessoa. (José)

Q6 - Você tem curiosidade em conhecer as pessoas a partir do toque e/ou contato com seus corpos?

Não sei não, acho que é, um assim eu tenho medo da pessoa não gostar. (Paulo)

Olha, eu tenho vergonha pra caramba, entendeu? Porque eu tenho muita vergonha, muito assim, receio de eu querer sei lá, tocar na pessoa, a pessoa não entender o meu lado, entendeu? E levar para a ignorância. (Mauro)

Aham, gostaria de pode senti o corpo das pessoas, das mulher também seria legal, pra gente saber direito como elas é. (José) 


\section{Discussão}

DOI: $10.5902 / 198468628535$

As palavras "magra" e "gorda" visitaram a fala de todos os entrevistados; porém, as representações de corpo ideal para os alunos com cegueira congênita apresentaram algumas aproximações e distanciamentos. Paulo, ao admitir que o modelo de corpo ideal fosse do tipo "nem muito gorda, nem muito magra" quando comparado ao apresentado por José, como sendo "um corpo médio, magra, tem que ser alta né, sarada, tem que ser uma pessoa musculosa", evidencia que ambos se aproximam das representações de corpos ideais propalados na contemporaneidade a partir do senso comum, que segundo Moscovici (2004) serve de estrutura ou núcleo fundante a partir da/do qual se estabelecem as representações sociais.

Destarte, é possível compreender que as representações de corpo ideal/perfeito para alguns dos participantes com cegueira congênita assemelham-se às representações sociais cunhadas nas e pelas objetivações sociais, culturais e históricas.

De acordo com Souza (2004), Berger (2006) e Brasílio (2007) esse modelo de corpo idealizado e naturalizado nas e pelas relações e práticas sociais caminham entre o corpo magro (para as mulheres) e o corpo "sarado" ou musculoso (para os homens), negandose, principalmente, aquele arquétipo constituído pela figura da pessoa gorda.

O fato de Mauro sinalizar sua preferência por corpos ou pessoas (neste caso se referia às mulheres) "gordinhas" e "cheinhas", secundarizando formas físico-corpóreas como estatura e magreza, pode não significar, necessariamente, um desconhecimento dos modelos ou padrões corporais hegemônicos marcados fortemente pela estrutura muscular e pela magreza. Evidencia-se, no entanto, que o tempo definido como sendo de "tolerância zero" perante o excesso de gordura corporal (NOVAES, 2008), não estava presente na avaliação e apreciação estética apresentada por esse participante.

Ao expressarem algumas compreensões a respeito das práticas cirúrgicas (como as plásticas e implantes de silicone) realizadas por algumas mulheres, partindo-se de uma questão que tratou de indagar sobre a influência da tevê na construção de um modelo de beleza, perceber-se-á uma sensível conexão entre a beleza e o corpo, evidenciando que apreendem que ter um corpo perfeito também significaria ser belo. 
DOI: $10.5902 / 198468628535$

Dessa feita, a análise dos enunciados permitiu identificar a influência da tevê no estabelecimento de alguns referenciais de beleza e estética. Para alguns participantes, a mídia televisiva ajudaria a propagandear práticas e serviços que comumente são utilizadas pelas mulheres, intuindo atender a um modelo de beleza corporal reconhecido e valorizado social e culturalmente, com destaque para as cirurgias plásticas e implantes de silicone.

Segundo Simões (2008) a mídia exerce influência direta no comportamento e nos sentidos das pessoas cegas no concernente às suas perspectivas sobre o universo da beleza, ressaltando-se também que essa influência muitas vezes acontece de maneira indireta, na medida em que as pessoas videntes que convivem com elas também contribuem para reproduzir e reforçar tais sentimentos e/ou comportamentos advindos do contexto midiático.

Nessa esteira, os artistas e/ou pessoas famosas, que estão sempre em condição de destaque neste espaço midiático, foram destacados nas falas dos entrevistados (direta ou indiretamente) como peças fundamentais neste processo de valorização de práticas, produtos e costumes ligados ao universo da beleza corporal.

Portanto, como destaca Berger (2006) as atrizes, atores e artistas têm demonstrado ao longo dos tempos uma importância nuclear na divulgação, propagação e imposição de modelos de beleza corporal e estética, auxiliando na venda de produtos e serviços neste mercado do corpo e da beleza, mostrando a partir de comerciais, entrevistas, filmes, novelas, reportagens, opiniões, práticas, atitudes e em seus belos e modelados corpos aquilo que seria a moda, tendência ou norma para um determinado tempo/espaço.

Neste sentido, pode-se sugerir que em algum grau ou perspectiva, os participantes compreendem o lugar protagonizado por esses corpos, ou melhor, por esses estandartes da indústria midiática e seus corpos esculturais e reificados.

Ressalta-se, assim, que os canais de comunicação de massa, especialmente a mídia televisiva, são decisivos nos processos de formação e circulação das representações sociais acerca de modelos e idealizações corporais hegemônicas nas sociedades contemporâneas (SÁ, 1998).

$\mathrm{Na}$ teoria das representações sociais a comunicação de massa é um dos principais pilares de sustentação e investigação teórica, dada sua importância e alcance na 
DOI: $10.5902 / 198468628535$

disseminação de valores, conhecimentos, costumes, conceitos e pensamentos sobre objetos, fenômenos e pessoas, agindo diretamente nas práticas sociais e no mundo no qual se encerra (MOSCOVICI, 2004).

De acordo com Paulo e Mauro o homem seria menos vaidoso ou preocupado com a beleza, destacado mais pela sua personalidade e atitudes, diferentemente da mulher que viveria às voltas com a vaidade e a beleza corporal. Esse achado se distancia de pressupostos teóricos defendidos por autores como Vigarello (2006) e Menezes (2011), na medida em que a beleza masculina idealizada e valorizada no modus cultural e social vigente estaria voltada para a preocupação crescente com a vaidade, estetização, performance e embelezamento de seus corpos.

Nas exposições feitas por José é possível encontrar ressonância com os modelos de corpos ideais institucionalizados para homens e mulheres na e pela contemporaneidade, particularmente, quando faz referências sobre corpos musculosos, práticas físicas e a existência e funcionalidade das academias de/para ginástica. Destacase assim que o atual cenário contemporâneo expresso pela imersão tanto do homem quanto da mulher no universo da beleza e de suas pronunciadas estruturas, feituras e buscas, foi sinalizado na fala deste aluno com cegueira.

Ao destacar o padrão de beleza para a mulher, atrelando-o ao aumento de músculos, este aluno externou aquilo que Vigarello (2006) apontou como a "feminização" da musculação, que por sua vez, não refletiria uma igualdade entre esses modelos (homem e mulher), somente uma livre alteridade. Portanto, o fato de algumas mulheres se sacrificarem com rotinas intermináveis de exercitação física para alcançar um corpo tonificado e com alto volume muscular, não significa que as mulheres estão em busca do mesmo perfil estético corpóreo masculino, mas, e, somente, provocando uma variabilidade para este perfil estético e corporal almejado pelo público feminino.

Observou-se, ainda, nos discursos que integraram as entrevistas, que as representações sociais em face ao corpo, apresentadas pelos participantes, se materializaram, principalmente, mediante decodificações imbricadas no seio de canais sensitivos como o tato e audição, e, ainda, por meio do campo estruturado da linguagem, consubstanciando a construção e o desenvolvimento do universo simbólico destas pessoas. Essa leitura corrobora com o que fora assinalado por autores como Amiralian 
(1997), Ormelezzi (2000), Batista (2005), Moura;Pedro (2006), Ventorini (2007), Simões (2008), Mariano (2016), Ganzarolli de Oliveira $(2002,2014)$ dentre outros.

Segundo Ganzarolli de Oliveira (2002) na vida, em geral, o estado de visão é apenas um dos muitos elementos a serem levados em consideração no que diz respeito ao conhecimento das pessoas. Dessa feita, as possibilidades de contemplação do belo mediante a realidade das pessoas cegas, revelam um processo que não se limita à percepção/sensação visual, ao passo que a beleza (e a arte) em suas variadas manifestações ao ser experenciada por meio do tato e da audição, permite eclodir uma concepção de beleza que se faz por meio da unidade, da singularidade da própria experiencia estética (GANZAROLLI DE OLIVEIRA, 2002).

Para Ormelezzi (2000) a linguagem funciona como um sistema simbólico ligado a um determinado grupo social e que permite ao cego organizar conceitos, experiências e todo o mundo ao seu redor. Portanto, as pessoas com cegueira prescindem da linguagem para poder se apropriar de informações que permitam conhecer e representar o corpo do outro, seja por meio da descrição que uma pessoa faz de outra ou a partir da auto-descrição que uma pessoa possa fazer acerca dos seus aspectos físicos e corporais, como nas palavras de Mauro: "É. Ai depois de algum tempo, que eu tava assim, com bastante amizade, ai eu pergunto para aquela pessoa mesmo como ela é."

Mariano (2016) analisou a relação de pessoas cegas com o contexto têxtil (roupas) e percebeu que ao pedir para avaliassem os tecidos apresentados, as mesmas recorriam a conceitos ou informações que ouviam ou aprendiam no dia a dia, denotando a pertinência da audição (captação de informações) e da aprendizagem de signos visuais e estéticos, por meio de explicações, conversas (escutas), de todo um universo de sentidos e perspectivas que se dão na esteira da comunicação "verbalizada".

A experiência de apreender, entender e admirar a beleza também é uma realidade para a pessoa com cegueira quando pensamos que é possível ouvir o belo, escutar o que é dito sobre o belo e até mesmo o que belo diz sobre si próprio, seja numa canção, num sussurro fraterno e cadenciado, na entonação ou timbre de uma voz que chega ou no poema declamado.

Como afirmou um dos participantes, em Simões (2008), os videntes oferecem valiosas informações e detalhes que tem muita importância na construção das análises estéticas 


\section{DOI: $10.5902 / 198468628535$}

que as pessoas cegas fazem das outras pessoas e, ainda, ao ouvir uma voz é possível se apaixonar pelos ouvidos.

Segundo Batista (2005) uma das principais diferenças entre a percepção visual e a tátil no seu processamento é que na visão pode-se ter a ideia do todo, de uma só vez, enquanto por meio do tato esse processamento é mais lento, fracionado, caminhando das partes para o todo, particularmente, nos casos onde o objeto a ser tocado é de tamanho tal que não pode ser capturado de uma única vez. Ainda, de acordo com Ganzarolli de Oliveira (2002) essa limitação tátil pode comprometer a maneira como se confere ou não status de beleza (ou feitura) às diversas realidade materiais, pois pode-se tocar num galho de árvore, mas não numa árvore inteira. O mesmo se aplicaria a situação em se toca num braço ou perna, mas nunca no corpo inteiro.

Para Laplane e Batista (2003) existem, então, ocasiões onde o tato não é possível, como objetos/coisas de grandes proporções (prédios, rios, aviões etc.), que estejam fora do alcance tátil (lua, estrela, sol) e situações em que seja proibido ou pouco convencional o seu uso, como animais selvagens e o corpo do outro ou partes dele.

Destarte, pode-se imaginar a dificuldade em apreender formas e estruturas corporais a partir de um referencial corporal que é estranho, que pertence ao outro. Dificuldade que é apontada por Mauro, ao expor que o tem vergonha de tocar o corpo do outro e que tem medo da pessoa tocada se sentir ofendida com aquela atitude. Contudo, como apontou um dos participantes do estudo de Simões (2008, p.48) "Dentro dos padrões que a sociedade impõem, em relação à beleza, é muito importante o tato 'né' [...] Então na verdade, você analisa na forma tátil pra você perceber como aquela pessoa é."Sobre as possibilidades da contemplação da beleza corporal e o contexto dessa dificuldade ou proibição do toque corporal, Ganzarolli Oliveira (2014) destaca a obra Les aveugles et la Société, de Pierre Henri, publicada em 1958, para enfatizar a inferioridade do cego, uma vez que não podia admirar a beleza (feminina) visualmente e tampouco apalpá-la. Embora a referida obra trate como um estado de "inferioridade", preferir-se-á a abordagem de Lebedeff (1994) ao admitir que conhecer ou explorar o corpo do sexo oposto é sempre difícil para a pessoa cega, principalmente numa cultura em que o toque é proibido, limitado ou controlado.

Ganzarolli de Oliveira (2014) ao questionar a abordagem da educadora Viviane Sarraf, a qual destaca a importância de todos os sentidos para que se possa contemplar uma obra 
DOI: $10.5902 / 198468628535$

de arte (a sua manifestação estética), pondera que a beleza impressa na arte não seria possível por meio de sentidos como olfato e o paladar, lançando a seguinte indagação sobre esses dois sentidos: "Podem perceber o que é belo?". Ainda, em Ganzarolli de Oliveira (2002) tem-se a menção da importância do olfato apenas em tarefas como a orientação espacial das pessoas cegas, permitindo que identifiquem locais por meio dos odores

Porém, o participante José ao descrever algumas particularidades da beleza refletida nas e pelas mulheres, destacou: “(...) é cheirosa claro, a pessoa tem que tá perfumada”. No estudo de Simões (2008) um dos participantes com cegueira também mencionou a importância primordial do cheiro ao definir aquilo que compreendia como beleza. Isto posto, é possível que o olfato tenha alguma importância no processo de idealização da beleza (padrões estéticos) de pessoas cegas, revelando um cenário que ainda precisa ser melhor investigado, antes de atestar que não exerce efeito na dimensão da beleza.

Por fim, em Ganzarolli De Oliveira (2002) é possível pensar a beleza no contexto das pessoas cegas a partir de uma inevitável ruptura ou ressignificação dos modelos ou padrões estéticos idealizados e projetados no seio dos estudos da Estética (enquanto ramo da Filosofia), possibilitando subverter o privilégio natural que o homem conferiu ao olhar no momento de se falar e discutir a beleza, abordando-a apenas e, somente, como assunto visual.

\section{Conclusão}

Nota-se que as representações, sentidos e significados nas falas dos entrevistados vão ao encontro de alguns pressupostos teóricos no campo das representações sociais, principalmente, aqueles que tratam de enfatizar que as representações do "senso comum" são conhecimentos mutáveis e transitórios. Essas representações modificam-se a partir das próprias práticas sociais ao mesmo tempo em que exercem influência direta sobre as mesmas, num movimento dialético e dinâmico.

Por meio dos procedimentos metodológicos empregados e, invariavelmente, pelas rotinas empreendidas junto às pessoas com cegueira congênita, pode-se constatar que o corpo, com suas formatações físico-anatômicas, funcionalidades e diversidade estética, ainda definem um horizonte pouco explorado e conhecido das pessoas com cegueira, na medida em que poucas experiências e vivências corporais são oferecidas às mesmas. 


\section{DOI: $10.5902 / 198468628535$}

Ao visualizar uma contemporaneidade frequentemente marcada por uma busca incansável pelo corpo belo/perfeito, tornando a beleza quase que sinônimo desta condição/estado, indiscutivelmente, remete-se a observação de um estado de conflitos e anseios que emergem no palco das relações e materializações sociais, políticas e econômicas. No entanto, no que concerne ao presente estudo, pode-se ao menos sugerir que essa busca exacerbada por se enquadrar em perfis corporais e estéticos dominantes pareceu não exercer tantas pressões e inquietudes no universo das pessoas com cegueira.

A beleza refletiva no e pelo corpo, palco de fenômenos como o culto ao corpo e de um mal-estar no seio da contemporaneidade, dando cor e ritmo aos relacionamentos sociais e afetivos, parece não receber tão honroso destaque na vida de pessoas com cegueira congênita.

O tato, a linguagem e a audição se mostraram mecanismos importantes para o desenvolvimento das representações sociais de beleza físico-corpórea e para o estreitamento com o mundo sensível sobre o qual se apresenta a beleza nas práticas e objetivações sociais de pessoas com cegueira. Em particular, os relatos, explicações e detalhes oferecidos por colegas ou pessoas próximas se mostraram imprescindíveis para que as pessoas com cegueira pudessem construir uma projeção corporal e estética daqueles com quem se relacionavam.

A análise das narrativas apresentadas por pessoas com cegueira pode oferecer significados, sentidos e leituras estéticas múltiplas ao tecido da estética e da beleza corporal. Considera-se, por fim, a necessidade de outras pesquisas que objetivem, de alguma maneira, prosseguir por alguns caminhos anunciados por este estudo, como o universo das representações sociais de corpo e os processos de simbolização e construções imagéticas relacionadas ao contexto das pessoas com cegueira congênita, intencionando a superação de estigmas e preconceitos que se cristalizam nas e pelas práticas e relacionamentos ao longo dos períodos históricos.

\section{Referências}

AMIRALIAN, M. L. T. M. Compreendendo o cego: uma visão psicanalítica da cegueira por meio de desenhos-estórias. São Paulo: Casa do Psicólogo, 1997.

BARDIN, L. Análise de conteúdo. Tradução de Luís Antero de France. Lisboa: Edições 70, 1977. 
DOI: $10.5902 / 198468628535$

BATISTA, C. G. Formação de conceitos em crianças cegas: questões teóricas e implicações educacionais. Psic.: Teor. e Pesq., Brasília, v. 21, n. 1, abr. 2005. Disponível em: <http://www.scielo.br/scielo.php?script=sci_arttext\&pid=S010237722005000100003\&lng=pt\&nrm=iso >. Acesso em: 16 de dezembro de 2016.

BERGER, M. Corpo e identidade feminina. Tese de Doutorado. Faculdade de Filosofia, Letras e Ciências Humanas, USP, São Paulo, 2006, 295p.

BRASÍLIO, L. A. Um olhar sócio-histórico sobre a beleza: das amarras à alteridade. Tese de Doutorado. Universidade Estadual Paulista - Julio de Mesquita Filho, UNESP, Araraquara, 2007, 136p.

GANZAROLLI DE OLIVEIRA, J. V. Do essencial invisível: arte e beleza entre os cegos. Rio de Janeiro: Revan/FAPERJ, 2002.

.Pierre Villey e o mundo dos cegos: relato de uma ausência. Revista Integração, São Paulo, ano XX, n. 66, pp. 39-45, 2014.

LAPLANE, A. L. F.; BATISTA, C. G. Um estudo das concepções de professores de ensino fundamental e médio sobre a aquisição de conceitos, aprendizagem e defi ciência visual [Resumo]. Em: Associação Brasileira de Pesquisadores em Educação Especial (Org.). Anais do I Congresso Brasileiro de Educação Especial, IX Ciclo de Estudos sobre Deficiência Mental. São Carlos: UFSCar, 2003, pp. 14-15.

LEBEDEFF, T. B. Aprendendo com o toque: reflexões e sugestões para uma educação sexual adaptada ao portador de deficiência visual. Rev. Bras. Educação Especial, Marília, v. 2, n. 1, 1994, pp. 31-7.

MARIANO, R. F. G. A percepção sensorial do corpo vestido: uma análise têxtil sob o ponto de vista feminino. Dissertação (Mestrado). Programa de PósGraduação em Têxtil e Moda. Escola de Artes, Ciências e Humanidades, Universidade de São Paulo, São Paulo, 2016, $113 f$.

MATTHIESEN et al. Linguagem, corpo e Educação Física. Revista Mackenzie de Educação Física e Esporte, São Paulo, v. 7, n. 2, 2008, pp. 129-139.

MENEZES, F. Dia do Homem: cinco erros de beleza que detonam a imagem masculina, 16 de julho de 2011. Disponível em: <http://msn.minhavida.com.br/conteudo/13324-Dia-do-Homem-cinco-erros-debeleza-que-detonam-a-imagem-masculina.htm?ordem=1\#gal>. Acesso em: 15 de janeiro de 2017. 
MOSCOVICI, S. Representações sociais: investigações em psicologia social. Trad. Do inglês por Pedrinho A. Guareschi. 2ª ed. Petrópolis, RJ: Vozes, 2004.

MOURA, G. R. de; PEDRO, E. N. R. Adolescentes portadores de deficiência visual: percepções sobre sexualidade. Rev. Latino-Am. Enfermagem, Ribeirão Preto, v. 14n. 2, abr. 2006. Disponível em: <http://www.scielo.br/scielo.php?script=sci_arttext\&pid=S010411692006000200011 \&lng=pt\&nrm=iso >. Acesso em 05 de janeiro de 2017.

NOVAES, J. V. Vale quanto pesa... sobre mulheres, beleza e feiúra. In: CASOTTI, Letícia; SUAREZ, Maribel; CAMPOS, Roberta Dias. O tempo da beleza: consumo e comportamento feminino, novos olhares. Rio de Janeiro: Senac Nacional, 2008, pp. $144-175$.

NOVAES, J. V. VILHENA, J. de. De Cinderela a moura torta: sobre a relação mulher, beleza e feiúra. Interações, jan-jun. 2003, vol.8, no.15, p.9-36.

ORMELEZZI, E. M. Os caminhos da aquisição do conhecimento e a cegueira: do universo do corpo ao universo simbólico. Dissertação de Mestrado, Faculdade de Educação da USP, São Paulo, 2000, f. 273.

SÁ, C. P. A construção do objeto de pesquisa em representações sociais. Rio de Janeiro: EdUERJ, 1998.

SAMPIERI, R. H.; COLLADO, C. H.; LUCIO, P. B. Metodologia de pesquisa. São Paulo: McGraw-Hill, 2006.

SIMÕES, L. Z. Beleza e deficiência visual. Trabalho de Conclusão de Curso (Graduação). Faculdade de Educação Física, Universidade Estadual de Campinas, Campinas, S.P. [s.n.], 2008.

SOUZA, A. F. C. O percurso dos sentidos sobre a beleza através dos séculos: uma análise discursiva. Dissertação (Mestrado em Linguística). Instituto de Estudos e Linguagem, UNICAMP, Campinas, 2004, 224p.

VENTORINI, S. E. A experiência como fator determinante na representação espacial do deficiente visual. Dissertação (Mestrado). Instituto de Geociências e Ciências Exatas. Universidade Estadual Paulista, Rio Claro, 2007, $225 f$.

VIGARELLO, G. História da beleza. Tradução de Léo Schlafman. Rio de Janeiro: Ediouro, 2006. 
VILELAS, J. Investigação: o processo de construção do conhecimento. Lisboa: Edições Sílabo, 2009.

\section{Correspondência}

Everton Luiz de Oliveira- Universidade em Bebedouro, R. Prof. Orlando França de Carvalho, Centro. CEP:14701-070, Bebedouro, São Paulo, Brasil.

Th is work is licensed under a Creative Commons Attribution-NonCommercial 4.0 International (CC BY-NC 4.0) 